Research Article

\title{
Characterization of Endogenous Auxins and Gibberellins Produced by Chlorella sorokiniana TH01 under Phototrophic and Mixtrophic Cultivation Modes toward Applications in Microalgal Biorefinery and Crop Research
}

\author{
Thi Cam Van Do, ${ }^{1,2,3}$ Dang Thuan Tran, ${ }^{4}$ Truong Giang Le, ${ }^{1,4}$ and Quang Trung Nguyen $\mathbb{D}^{1,2}$ \\ ${ }^{1}$ Graduate University of Science and Technology, Vietnam Academy of Science and Technology, 18 Hoang Quoc Viet, Cau Giay, \\ Ha Noi, Vietnam \\ ${ }^{2}$ Center for Research and Technology Transfer, Vietnam Academy of Science and Technology, 18 Hoang Quoc Viet, Cau Giay, \\ $\mathrm{Ha}$ Noi, Vietnam \\ ${ }^{3}$ Department of Chemical Technology, Hanoi University of Industry, No. 298 Cau Dien, Bac Tu Liem, Ha Noi, Vietnam \\ ${ }^{4}$ Institute of Chemistry, Vietnam Academy of Science and Technology, 18 Hoang Quoc Viet, Cau Giay, Ha Noi, Vietnam
}

Correspondence should be addressed to Quang Trung Nguyen; nqt79@yahoo.com

Received 16 March 2020; Accepted 19 May 2020; Published 4 June 2020

Academic Editor: Casimiro Mantell

Copyright (c) 2020 Thi Cam Van Do et al. This is an open access article distributed under the Creative Commons Attribution License, which permits unrestricted use, distribution, and reproduction in any medium, provided the original work is properly cited.

\begin{abstract}
Microalgae have been reported to produce endogenous phytohormones including auxins, gibberellins, cytokinins, brassinosteroids, and abscisic acid. Methanol residual released from microalgal lipid extraction usually contains a variety of bioactive compounds including the phytohormones; however, they are poorly characterized and used for other applications. This study aimed at investigating auxin, gibberellin, and cytokinin production of C. sorokiniana TH01 under phototrophic and mixtrophic cultivations. Moreover, endogenous auxins, gibberellins, and cytokinins in methanol residual obtained from the algal lipid extraction were characterized using HPLC-ESI-MS/MS toward application for crop and biorefinery research. Data showed that endogenous indole-3-acetic acid (IAA), 3-indolepropionic acid (IPA), gibberellin A4 (GA4), and gibberellin A7 (GA7) were detected in C. sorokiniana TH01 biomass. Under the phototrophic mode, total auxin and GA levels were reduced to 0.98 and $9.65 \mu \mathrm{g} / \mathrm{g}$ DW under salt stress $(20 \mathrm{~g} \mathrm{NaCl} / \mathrm{L})$ from 3.59 to $24.71 \mu \mathrm{g} / \mathrm{g} \mathrm{DW}$, respectively, measured for the control. Similarly, total auxins and GAs were also decreased to 0.56 and $2.86 \mu \mathrm{g} / \mathrm{g} \mathrm{DW}$, respectively, under mixtrophic growth with $6 \mathrm{~g}$ glucose/L. Total auxins and GAs determined in the water algal extract were 1062.7 and $2000.1 \mu \mathrm{g} / \mathrm{L}$, respectively. Treatment with higher 40\% (v/v) of the algal extract triggered earlier seed germination of rice and tomato plants in 2 and 1 days, respectively. Our new findings in capability of C. sorokiniana TH01 in endogenous phytohormone production contain fundamental merits for further optimization of the algal production (i.e., cultivation modes, conditions, lipids, biomass productivity, and hormone levels) to be used for biorefinery.
\end{abstract}

\section{Introduction}

There is a vast increasing demand for microalgal-derived biomolecules in crop production (biostimulants and biofertilizers) [1, 2], food and feed [3], pharmaceutical [4], nutraceutical [5], and biofuel production [6]. Biorefinery is a comprehensive approach that could fractionize all biocompositions of microalgal biomass for these specific uses. In the field of agriculture, it has been reported that algal culture medium, algal extract, and algal biomass enhanced crop seed germination and plant growth (root length, plant height, branch, and leave and flower increase) [7-11]. Although some good results have been achieved on application of microalgal products as fertilizers, biostimulants, and 
regulators of plant growth, these studies poorly provided analytical techniques for characterization of these algal products. The profile and content of algal product-constituted biomolecules which play the main roles in catalyzing crop seed germination as well as plant growth should be elucidated for providing basic understanding and guidance for specific applications in agriculture [8].

It has been reported that microalgae could produce exogenous [12] and endogenous phytohormones [13-18]. The most common phytohormones reported to produce in microalgae were auxins [16], gibberellins [14], cytokinins [16], brassinosteroids [13, 14], and abscisic acid [19]. The production capacity of phytohormones in green algae such as Chlorella sp. [13, 18], Scenedesmus sp. [12, 20], and Acutodesmus dimorphus [21] has been reported recently. Phytohormones are usually present in microalgae at very low concentration with various structures, and thus determination of phytohormone levels in microalgae is extremely challenging. Therefore, the analytical method used for microalgal hormones requires high sensitive and selective analytical systems. Fortunately, high-performance liquid chromatography coupled with mass spectrometer detector (HPLC-MS), an advanced technique, has been used for successful structure elucidation and quantification of multiclass of phytohormones in a variety of biomass matrixes such as macroalgae [15], plants [22], seeds [23], and microalgal biomass $[13,14,16,18,20]$.

Although numerous studies have been carried out to use Chlorella sorokiniana as a promising candidate for lipid production under both autotrophic and heterotrophic cultivation modes $[24,25]$, none of research has investigated the capability of the algal strain in production of endogenous phytohormones. The use of algal biomass-filtered media for crop production is absolutely interesting because the method can simultaneously utilize exogenous algal phytohormones and residual nutrients in algal culture medium for stimulating plant growth. However, the utilization of whole algal biomass for the crop production purpose only might be wasteful. This is because microalgal biomass is considered as a high-value biomaterial which usually contains large content of lipids and/or carbohydrates and proteins [26]. In regard to biorefinery, microalgal lipids and carbohydrates are promising feedstocks for liquid biofuel (biodiesel, bioethanol, etc.) production [27], whereas proteins [28] are potential materials for feed/food formulation [29]. On the other hand, lipid and sugar extractions are prerequisite steps in biofuel production from algal biomass. The extraction of lipids is usually performed with biphasic solvents of chloroform/methanol or hexane/methanol to obtain lipids dissolved in less polar solvents (e.g., chloroform and hexane) [30], while the methanol phase contains pigments and variety of bioactive compounds (phytohormones, antibacteria biomolecules, anticancer biomolecules, etc.) [31]. To the best of our knowledge, there are only few studies reporting to use the methanol extracts derived from Chlorella vulgaris and Scenedesmus quadricauda to study biostimulating effects on lettuce seedlings [32], morphological and molecular responses in Beta vulgaris L. [33], and biological activity on soil [34]. Moreover, although efforts have been made on application of advanced analytical techniques such as solidstate ${ }^{13} \mathrm{C}$ magic angle spinning nuclear magnetic resonance (MAS NMR), Fourier-transform infrared spectroscopy (FTIR), inductively coupled plasma atomic emission spectroscopy (ICP-EOS), and Elementar vario MACRO CNS for characterization to understand the complexity and heterogeneity of various bioactive components of methanol extracts of Chlorella vulgaris and Scenedesmus quadricauda, the modes of action as biostimulants of these compounds remained unknown [33]. Particularly, these bioactive compounds are present in very low concentration, and thus their synergistic activity needs to be taken into account but is still largely unexplored. We have made a hypothesis that endogenous algal phytohormones released out from algal biomass will migrate to methanol phase during lipid extraction. Therefore, collection of methanol phase for concentrating phytohormones would be advantageous for agricultural research. However, possibility of the use of the methanol extract for crop application depends on profile and quantity of the phytohormones contained in the extract. Therefore, profiling and quantification of the phytohormones in the methanol algal extract is necessary as it provides a basic understanding of the extract toward reasonable applications in crop research.

Therefore, the objective of this study is to (i) investigate capability of C. sorokiniana TH01 in endogenous phytohormone (auxins, gibberellins, and cytokinins) production under phototrophic and mixtrophic cultivation modes, (ii) to quantify auxin, gibberellin, and cytokinin levels in residual methanol extract obtained from lipid extraction of $C$. sorokiniana TH01 by high-performance liquid chromatography electrospray ionization tandem mass spectrometric (HPLC-ESI-MS/MS) technique, and (iii) to study biostimulating effects of the residual methanol extract on seed germination rate of rice and tomato plants.

\section{Materials and Methods}

2.1. Chemicals and Reagents. Fourteen standard chemicals of three popular groups of phytohormones including cytokinins (kinetin (Ki), trans-zeatin riboside $(t Z R)$, isopentenyladenine (iP), N6-(2-isopentenyl) adenine (2iP), $\mathrm{N}(6)$-isopentenyladenosine (iPR), trans-zeatin ( $t Z$ ), 6-benzylaminopurine (BA), and dihydrozeatin riboside (DHzR)), gibberellins (gibberellic acid (GA3), gibberellin A4 (GA4), and gibberellin A7 (GA7)), and auxins (indole-3-butyric acid (IBA), 3-indolepropionic acid (IPA), indole-3-carboxylic acid (ICA), and indole-3-acetic acid (IAA)) and HPLC-grade formic acid, methanol, chloroform, methanol, and hydrochloric acid (37\%) were obtained from Merck KGaA (Darmstadt, Germany). Tridecanoic acid methyl ester (C13:0) ( $\geq 98 \%)$, Supelco 37 component FAME Mix $(\geq 97 \%)$, and hexane $(\geq 95 \%)$ were purchased from SigmaAldrich, Inc. (St. Louis, MO, USA). Standard solutions of all phytohormones were prepared in methanol of HPLC analytical grade, by dissolving and homogenizing the compounds using vortex (ZX4, Velp Scientifica, Italy). The stock solution was made with concentration of $1000 \mathrm{ppm}$ and then further diluted to the desired concentration of working 
solutions. The phytohormones mixtures were prepared prior to the HPLC analysis. Once the analysis ended, the solutions of single compounds were stored in the refrigerator at $-4^{\circ} \mathrm{C}$ no longer than 3 weeks.

Seed of rice (TH5-1) and tomato (HT7, HT21) plants were obtained from Vietnam National University of Agriculture (Trau Quy, Gia Lam, Ha Noi, Vietnam).

2.2. Microalgal Strain and Biomass Production. Chlorella sorokiniana TH01 (C. sorokiniana TH01) was isolated and purified from wastewater of a Quang Ninh's coal-fired power plant (Quang Ninh Province, Vietnam). The algal strain was maintained on Petri dish containing solid agar BG-11 medium which consists of $(\mathrm{g} / \mathrm{L}) \mathrm{NaNO}_{3}, 1.5$; $\mathrm{K}_{2} \mathrm{HPO}_{4}, 0.04 ; \mathrm{MgSO}_{4} \cdot 7 \mathrm{H}_{2} \mathrm{O}, 0.075 ; \mathrm{CaCl}_{2} \cdot 2 \mathrm{H}_{2} \mathrm{O}, 0.036$; citric acid, 0.006; ferric ammonium citrate, 0.006; EDTA (ethylenediaminetetraacetic acid), $0.001 ; \mathrm{Na}_{2} \mathrm{CO}_{3}, 0.02$; mix A5 solution, $1 \mathrm{~mL} / \mathrm{L}$; and agar, 10. Mix A5 consists of $\mathrm{H}_{3} \mathrm{BO}_{3}$, $2.86 \mathrm{~g} / \mathrm{L} ; \mathrm{MnCl}_{2} \cdot 4 \mathrm{H}_{2} \mathrm{O}, 1.81 \mathrm{~g} / \mathrm{L} ; \mathrm{ZnSO}_{4} \cdot 7 \mathrm{H}_{2} \mathrm{O}, 0.222 \mathrm{~g} / \mathrm{L}$; $\mathrm{Na}_{2} \mathrm{MoO}_{4} \cdot 2 \mathrm{H}_{2} \mathrm{O}, 0.39 \mathrm{~g} / \mathrm{L} ; \mathrm{CuSO}_{4} \cdot 5 \mathrm{H}_{2} \mathrm{O}, 0.079 \mathrm{~g} / \mathrm{L}$; and $\mathrm{Co}\left(\mathrm{NO}_{3}\right)_{2} \cdot 6 \mathrm{H}_{2} \mathrm{O}, 0.0494 \mathrm{~g} / \mathrm{L}$.

The seed algal culture was prepared by inoculating the algal solids grown on the Petri dishes to Erlenmeyer flasks containing $150 \mathrm{~mL}$ liquid BG-11 medium. The inoculation was grown phototrophically under continuous light illumination at $60 \mu \mathrm{mol} / \mathrm{m}^{2} \cdot \mathrm{s}$ and temperature of $25 \pm 0.5^{\circ} \mathrm{C}$ with shaking rate of $50 \mathrm{rpm}$ for eleven days to reach the peak of the exponential phase with achieved cell concentration of $12.4 \times 10^{7}$ cells $/ \mathrm{mL}$ (biomass concentration of approximation of $0.992 \mathrm{~g} / \mathrm{L}$ ).

For biomass production, the obtained seed algal culture was inoculated into Simax 5 L glass bottles (KAVALIERGLASS, a.s., Praha, Czech Republic) containing $4 \mathrm{~L}$ of the sterilized BG-11 medium. The phototrophic growth variables including light intensity, light dark cycle, temperature, and $\mathrm{CO}_{2}$ aeration rate were controlled at $115 \mu \mathrm{mol} / \mathrm{m}^{2} \cdot \mathrm{s}$, $16 \mathrm{~h} / 8 \mathrm{~h}, 27^{\circ} \mathrm{C}$, and $0.1 \mathrm{vvm}\left(\mathrm{CO}_{2} 2 \%\right)$, respectively [26]. Algal biomass production under salt stress was performed using $\mathrm{NaCl}$ concentration of 5, 10, 15, and $20 \mathrm{~g} / \mathrm{L}$. Mixtrophic cultivation of C. sorokiniana TH01 was carried out with supplement of glucose concentration of 2,4 , and $6 \mathrm{~g} / \mathrm{L}$ in BG-11 medium under the same light, temperature, and $\mathrm{CO}_{2}$ aeration conditions as mentioned above in the phototrophic mode. Samples were daily taken at 10 am to determine biomass growth. The algal biomass production was terminated and harvested at day 15 of the cultivation (stationary phase). The experiment was performed in triplicate $(n=3)$.

The outdoor cultivation of C. sorokiniana TH01 in $500 \mathrm{~L}$ BG-11 was performed in a raceway pond under a greenhouse following a protocol as described in Tran et al. [26]. The daily light and temperature variation of the outdoor cultivation was 560013340 lux and $23.4-27.5^{\circ} \mathrm{C}$, respectively. Samples were daily taken at $10 \mathrm{am}$ to determine biomass growth. The algal biomass production was terminated and harvested at day 15 of the cultivation (stationary phase). The experiment was performed in duplicate $(n=2)$.
Biomass was harvested by centrifugation and washed several times by Millipore water followed by cool drying at $25^{\circ} \mathrm{C}$ for $24 \mathrm{~h}$ using a cool dryer (MSL300MT, Mactech Co., Ltd, Vietnam) to obtain flake biomass. The flake form was further ground by a mini grinder (800A, LaLiFa Co., Ltd, Vietnam) to obtain fined algal powder $(<5 \mu \mathrm{m})$ for other uses.

2.3. Microalgal Growth Measurement and Lipid Analysis. Total dry biomass weight expressed as $\mathrm{g} / \mathrm{L}$ of the algal biomass was determined gravimetrically after filtration of the algal suspension with filter paper (Whatman $0.45 \mu \mathrm{m}$, $47 \mathrm{~mm}, \mathrm{UK})$ and drying at $105^{\circ} \mathrm{C}$ for $24 \mathrm{~h}$. The specific growth rate $(\mu, 1 / \mathrm{d})$ was determined from exponential phase of the growth curve using the following modelling equation:

$$
\mu=\frac{\left(\ln X_{2}-\ln X_{1}\right)}{t_{2}-t_{1}},
$$

where $X_{2}$ and $X_{1}$ are biomass concentrations $(\mathrm{g} / \mathrm{L})$ measured at time slot $t_{2}$ (day) and $t_{1}$ (day), respectively.

Lipid content of the Chlorella sp. derived as total fatty acid methyl esters (FAME) was extracted via in situ transesterification method of the algal biomass with $\mathrm{HCl} /$ methanol $(5 \% \mathrm{v} / \mathrm{v})$ as homogeneous catalyst at $85^{\circ} \mathrm{C}$ for $1 \mathrm{~h}$ followed by quantification using gas chromatography coupled with flame ionization detector (GC-FID) as described in Laurens et al. [35]. The FAME content in algal cell was calculated as FAME weight determined by GC-FID against a unit weight of dry cell weight (DCW).

2.4. Extraction of Phytohormones. The conventional lipid extraction procedure applied in this study was modified from a method that was described in Laurens et al. [35]. In brief, the dry algae powder of Chlorella's biomass of approximately $200 \mathrm{mg}$ was mixed with $3 \mathrm{~mL}$ of solvent mixture of chloroform/methanol/concentrated $\operatorname{HCl}(2: 1: 0.002, \mathrm{v} / \mathrm{v} /$ v) in $15 \mathrm{~mL}$ cylindrical glass tubes. The algae-solvent mixture was then mixed on the Vortex (ZX4, Velp Scientifica, Italy) for 5 minutes, followed by ultrasound (Ultrasonic Cleaner) in the ultrasonic tank containing ice for 60 minutes below $10^{\circ} \mathrm{C}$. The postultrasound mixture was further vortexed for 5 minutes followed by ultrasonication for 30 minutes for extraction of active substances into the methanol phase. After the vortex and ultrasonic treatment steps, the mixture was centrifuged (Z206A, HERMLE, Germany) at a rate of $5,000 \mathrm{rpm}$ for $5 \mathrm{~min}$ at $4^{\circ} \mathrm{C}$ to separate layers of the solvents and algal biomass. The chloroform phase containing lipids was withdrawn by micropipettes while the methanol phase containing phytohormones and residual biomass was filtered through PTTE filters $(0.22 \mu \mathrm{m})$ to completely remove the algal biomass debris. The extraction was repeated three times and methanol phases were summed up before drying under nitrogen and reconstituted in $1 \mathrm{~mL}$ methanol and further filtered through PTTE filters $(0.22 \mu \mathrm{m})$ for quantitative determination of phytohormones using the HPLCESI-MS/MS system. During extraction, a cocktail of 14 standard phytohormones listed above was added at 
concentration of $500 \mathrm{ppb}$ to evaluate recovery of the extraction procedure. Experiments were performed in six replicates $(n=6)$.

To produce algal extract for seed germination study of rice and tomato plants, $100 \mathrm{~g}$ dry biomass powder of $C$. sorokiniana TH01 (produced phototrophically in the raceway pond) was dispersed in $1.5 \mathrm{~L}$ chloroform/methanol/ concentrated $\mathrm{HCl}(2: 1: 0.002, \mathrm{v} / \mathrm{v} / \mathrm{v})$ in a $2 \mathrm{~L}$ Duran glass bottle in an ice bath and stirred with a magnetic stirrer at $100 \mathrm{rpm}$ overnight. The extraction was repeated three times and methanol phase was obtained by centrifugation and summed up followed by methanol removal by a rotary evaporator (RV V3, IKA ${ }^{\circledR}$-Werke GmbH \& Co. KG, Staufen, Germany). The dense solid was reconstituted into $500 \mathrm{~mL}$ Millipore water (making a crude extract having $\mathrm{pH}$ of 3.5) and neutralized to $\mathrm{pH} 7.0$ by addition of $\mathrm{NaOH} 6 \mathrm{~N}$ and used as seed premier for study of germination of rice and potato seeds. Several volumes of the Millipore water extract was further filtered with PTTE filters $0.22 \mu \mathrm{m}$ before employing as samples for quantification of phytohormones using the HPLC-ESI-MS/MS system.

2.5. Instrumentation and Conditions for Phytohormone Analysis. The instrumentation included a high-performance liquid chromatography (HPLC, UltiMate 3000, Thermo Scientific) connected to a mass spectrometry detector (LCQ Fleet, Thermo Scientific) equipped with an electron spray ionization source (HPLC-ESI-MS/MS). Phytohormones were separated on a C18 reverse phase HPLC column $(3 \mu \mathrm{m}$, $150 \times 2.1 \mathrm{~mm}$, Part No. 25303152130, Thermo Scientific) with 02 mobile phases including phase A (Millipore water with $0.1 \%$ formic acid) and phase B (Methanol with $0.1 \%$ formic acid) at the same flow rate of $0.3 \mathrm{~mL} / \mathrm{min}$ and temperature of $40^{\circ} \mathrm{C}$. Separations were performed using a gradient of increasing methanol content. The initial gradient of methanol was kept at $30 \%$ for $3 \mathrm{~min}$, increased linearly to $90 \%$ at $10 \mathrm{~min}$ and later maintained for $2 \mathrm{~min}$, decreased linearly to $30 \%$ at $13 \mathrm{~min}$, and later maintained for $2 \mathrm{~min}$. After $0.1 \mathrm{~min}$, the initial conditions were restored and allowed to equilibrate for $15 \mathrm{~min}$.

For selection of diagnostic precursor-to-product ion transitions, each standard compound of plant hormones dissolved in methanol was directly infused into a hybrid triple quadrupole/linear ion trap mass spectrometer coupled with an electrospray ion (ESI) source using a $1 \mathrm{~mL}$ Hamilton syringe in a syringe pump at a flow rate of $0.6 \mathrm{~mL} / \mathrm{h}$. ESI-MS/ MS analysis was performed in both negative and positive ionization modes. In order to generate the highest signal intensities, mass spectrometry parameters including heater temperature, sheath gas flow rate, aux gas flow rate, sweep gas flow rate, spray voltage, capillary temperature, capillary voltage, and tube lens were optimized as $100^{\circ} \mathrm{C}, 45$ (arb), 25 $(\mathrm{arb}), 0(\mathrm{arb}), 3.6(\mathrm{kV}), 200^{\circ} \mathrm{C},-11(\mathrm{~V})$, and $-55.98(\mathrm{~V})$, respectively.

For quantitative analysis, the mixture of standard compounds were separated by the HPLC reversed-phase C18 column and scanned by the ESI-MS/MS detector in the selected ion monitoring (SIM) mode with respective ions presented in Table S1. The dwell time for each ion was $30 \mathrm{~ms}$ and each analyte had its own SIM window where possible. The SIM mode was used to monitor the precursor-toproduct ion transition. To determine the mass spectra and the retention time for each phytohormones, mix of fourteen analytes diluted in the range of concentration of 50,100, 500, 1000 , and $2000 \mathrm{ppb}$ was injected in the SIM-mode to establish the standard curve.

2.6. Validation of Phytohormone Analysis Method. The reliability of the developed analytical method was evaluated by the reproducibility, the recovery of extraction procedure, the sensitivity, and the linearity. Intra- and interday relative standard deviations (RSDs) of the retention time and peak area were chosen to determine the reducibility of the method. The intraday variation was determined by analyzing the standard mixture solution for six times within one day. For the interday variability test, the solution was examined on four successive days. The extraction recovery yields of fourteen phytohormones extraction conditions were investigated, analyzed at low (100 ppb), medium (450 ppb), and high $(1500 \mathrm{ppb})$ concentrations, according to the calibration curve ranges. The sensitivity and the linearity were also evaluated via the limits of detection (LOD), limits of quantification (LOQ), and the correlation coefficient $\left(R^{2}\right)$ of the calibration curves, respectively.

2.7. Biostimulating Experiments. The Millipore water algal extract obtained above with total concentration of phytohormones determined of $C_{0}$ was further diluted with Millipore water to different levels of $0.05 C_{0}, 0.1 C_{0}, 0.2 C_{0}, 0.3 C_{0}$, $0.4 C_{0}, 0.5 C_{0}$, and $C_{0}$ and used to treat seeds of rice and tomato plants at $30^{\circ} \mathrm{C}$ for $24 \mathrm{~h}$ and $6 \mathrm{~h}$, respectively. The control treatments were the seeds treated with Millipore water only. Each treatment contained 50 seeds. The treated seeds were then enclosed with moisturized cotton cloth in Petri dish and incubated at stable temperature of $30^{\circ} \mathrm{C}$ for 10 days. The germination rate was measured as ratio of the seeds germinated over total seeds used for each treatment.

2.8. Statistical Analysis. The experiments were performed in six replicates, and the results were presented as mean \pm S.D. of all six measurements. Statistical analysis was done using one-way ANOVA followed by post hoc Tukey's test (Graph pad V7), and a $p$ value of $<0.05$ was declared as significant. The statistical analysis was conducted using SPSS 22.0 (IBM, USA).

\section{Results and Discussion}

3.1. Verification of Precursor-to-Product Ion Transitions and HPLC Conditions. The structures of fourteen phytohormones are depicted in Figure S1. Standard solutions of the fourteen phytohormones were used to identify the appropriate precursor-to-product ion transitions. Kinetin (Ki), trans-zeatin riboside ( $t \mathrm{ZR}), \mathrm{N}^{6}$-(2-Isopentenyl) adenine (iP), $\mathrm{N}(6)$-isopentenyladenosine (iPR), trans-zeatin ( $t \mathrm{Z})$, 6- 
benzylaminopurine (BA), and dihydrozeatin riboside (DHzR) were analyzed in positive scan modes as $[\mathrm{M}+\mathrm{H}]^{+}$ ions (Figure S2), while the remaining seven compounds including gibberellic acid (GA3), gibberellin A4 (GA4), gibberellin A7 (GA7), indole-3-butyric acid (IBA), 3indolepropionic acid (IPA), indole-3-carboxylic acid (ICA), and indole-3-acetic acid (IAA) were assayed in negative scan mode as $[\mathrm{M}-\mathrm{H}]^{-}$ions (Figure S3). Precursor and characteristic product ions for each hormone were chosen and used to quantify the different hormones in algal extracts. MS/MS conditions were optimized to produce maximal signal of each hormone (Table S1). It was observed that seven phytohormones (Ki, $t \mathrm{ZR}, \mathrm{iP}, \mathrm{iPR}, t \mathrm{Z}, \mathrm{BA}$, and DHzR) (Figure S2) and other seven analytes (GA3, GA4, GA7, IBA, IPA, ICA, and IAA) (Figure S3) were separated clearly in positive and negative scan modes, respectively, under the established HPLC conditions.

3.2. Calibration Curves, Detection Limits, and Accuracy and Precision. Calibration curves were constructed by plotting the peak areas against phytohormones concentrations ranging from 50 to $2000 \mathrm{ppb}$. Data shown in Table S2 indicate that good linear correlations were achieved for all phytohormones with correlation coefficients of $R^{2}$ ranging from 0.999 to 1.0. The LODs and LOQs for fourteen phytohormones ranged from $3.56-156.74 \mathrm{ppb}$ and $10.80-474.97 \mathrm{ppb}$, respectively. Accuracy and precision of the method were evaluated by determination of recoveries and intra- and interday relative standard deviations (RSDs) by spiking standards at three concentrations of 100,450, and $1500 \mathrm{ppb}$ into algal extracts. The results revealed that the relative recoveries were determined between 86.7 and $114.8 \%$ (Table 1). The intra- and interday precisions for recoveries of the fourteen phytohormones were below 7.0\% and $7.2 \%$ (Table 2), respectively. The results demonstrated that the accuracy and precision of the developed method are reliable for the determination of phytohormones in algal biomass.

3.3. Effect of $\mathrm{NaCl}$ Concentration on Growth, Profile, and Levels of Auxins, Cytokinins, and Gibberellins Produced by C. Sorokiniana THO1 under Phototrophic Growth. Although stress with salt inhibits microalgal growth and lowers algal productivity, the approach has been employed as one of the alternative engineering strategies for enhancing lipid content of microalgal biomass. It was commonly reported that increasing $\mathrm{NaCl}$ concentration in culture media improves algal lipid content but decreases the algal growth (e.g., Scenedesmus obliquus and Chlorella vulgaris) [36, 37]. In consistence with the reported data, the C. sorokiniana TH01 used in this study also exhibited specific growth rate and biomass concentration decreasing from 0.72 to $0.231 /$ day and 0.96 to $0.55 \mathrm{~g} / \mathrm{L}$, respectively, when $\mathrm{NaCl}$ concentration increased from 0 to $20 \mathrm{~g} / \mathrm{L}$ (Table 3). Notably, the lipid content of C. sorokiniana TH01 derived in the form of fatty acid methyl esters (FAME) was determined as 19.13, 24.34, $33.48,39.75$, and $44.23 \% \mathrm{DCW}$ when $0,5,10,15$, and $20 \mathrm{~g} / \mathrm{L}$ $\mathrm{NaCl}$ were introduced as a medium composition.
TABLE 1: Recoveries of fourteen phytohormones spiked into algal extract samples $(n=6)$.

\begin{tabular}{lccc}
\hline Compound & \multicolumn{3}{c}{ Recovery $(\% ; n=6)$} \\
& $100 \mathrm{ppb}$ & $450 \mathrm{ppb}$ & $1500 \mathrm{ppb}$ \\
\hline Ki & $88.2 \pm 2.7$ & $87.2 \pm 5.8$ & $92.4 \pm 7.2$ \\
$t \mathrm{ZR}$ & $89.4 \pm 4.5$ & $91.7 \pm 3.2$ & $114.8 \pm 4.6$ \\
$\mathrm{iP}$ & $87.7 \pm 6.2$ & $94.4 \pm 6.9$ & $89.3 \pm 5.5$ \\
$\mathrm{iPR}$ & $88.9 \pm 3.5$ & $98.1 \pm 4.5$ & $88.2 \pm 6.7$ \\
$t Z$ & $98.3 \pm 5.6$ & $92.9 \pm 2.4$ & $99.5 \pm 7.7$ \\
$\mathrm{BA}$ & $95.2 \pm 9.0$ & $93.5 \pm 5.7$ & $103.7 \pm 9.5$ \\
$\mathrm{DHzR}$ & $93.2 \pm 5.8$ & $88.3 \pm 2.5$ & $100.5 \pm 8.4$ \\
GA3 & $99.1 \pm 7.3$ & $101.2 \pm 9.7$ & $98.7 \pm 4.7$ \\
GA4 & $95.6 \pm 10.2$ & $110.5 \pm 5.6$ & $86.7 \pm 1.3$ \\
GA7 & $91.5 \pm 6.7$ & $95.3 \pm 6.7$ & $93.5 \pm 6.9$ \\
IBA & $112.1 \pm 9.4$ & $97.3 \pm 7.3$ & $94.7 \pm 3.5$ \\
IPA & $108.3 \pm 8.6$ & $94.2 \pm 3.6$ & $96.4 \pm 2.5$ \\
ICA & $102.3 \pm 5.6$ & $88.4 \pm 5.6$ & $112.4 \pm 4.5$ \\
IAA & $98.4 \pm 6.8$ & $93.5 \pm 6.8$ & $109.5 \pm 3.5$ \\
\hline
\end{tabular}

Algal biomass samples used were of $C$. sorokiniana TH01 grown phototrophically in BG-11 medium. Kinetin $(\mathrm{Ki})$, trans-zeatin riboside $(t \mathrm{ZR})$, isopentenyladenine (iP), N6-(2-isopentenyl) adenine (2iP), N(6)-isopentenyladenosine (iPR), trans-zeatin $(t \mathrm{Z})$, 6-benzylaminopurine (BA), dihydrozeatin riboside (DHzR), gibberellic acid (GA3), gibberellin $A 4$ (GA4), gibberellin A7 (GA7), indole-3-butyric acid (IBA), 3-indolepropionic acid (IPA), indole-3-carboxylic acid (ICA), and indole-3-acetic acid (IAA).

Mass data for the crude C. sorokiniana TH01 extract revealed that none of phytohormones were detected in positive scan mode (Figure S4a). The poor identification of phytohormone profile of the crude algal extract compared to the standard solution was attributed to interferences caused by impurities which were present in the crude algal extract. However, negative scan mode resulted in better signals with four phytohormones of IAA, IPA, GA4, and GA7 identified (Figure S4b).

Data shown in Figure 1 indicate that the IAA, IPA, and GA7 contents determined for C. sorokiniana TH01 grown in BG-11 media under autotrophic without salt stress were $0.93,2.66$, and $20.87 \mu \mathrm{g} / \mathrm{g}$ dry weight (DW), respectively. The contents of IAA, IPA, and GA7 were observed to decrease to $0.49,2.55$, and $13.05 \mu \mathrm{g} / \mathrm{g} \mathrm{DW}$, respectively, when $\mathrm{NaCl}$ was supplied to BG-11 medium at concentration of $5 \mathrm{~g} / \mathrm{L}$. Levels of IAA, IPA, and GA7 continued to decrease to $0.44,1.98$, and $8.71 \mu \mathrm{g} / \mathrm{g} \mathrm{DW}, 0.36,1.02$, and $6.8 \mu \mathrm{g} / \mathrm{g} \mathrm{DW}$, and $0.18,0.8$, and $3.39 \mu \mathrm{g} / \mathrm{g} \mathrm{DW}$, respectively, when $\mathrm{NaCl}$ concentration accordingly increased to 10,15 , and $20 \mathrm{~g} / \mathrm{L}$, respectively. Total auxins were measured to decrease from 3.59 to $0.98 \mu \mathrm{g} / \mathrm{g}$ DW when $\mathrm{NaCl}$ concentration increased from 0 to $20 \mathrm{~g} / \mathrm{L}$, respectively. The reduction of auxin levels measured for $C$. sorokiniana TH01 under salt-stress conditions is in agreement with observation of $\mathrm{Du}$ et al. [38], who reported $72 \%$ decrease of endogenous IAA content in rice after experiencing 3 days of drought stress. However, in another study, growth of rice in a cold condition for 3 days and a heat stress for $6 \mathrm{~h}$ resulted in 1.6-fold and 1.3-fold increases of IAA levels [39], respectively.

In contrast, GA4 content was observed to steadily increase from $2.84 \mu \mathrm{g} / \mathrm{g}$ DW to $6.26 \mu \mathrm{g} / \mathrm{g}$ DW when $\mathrm{NaCl}$ concentration increased from 0 to $20 \mathrm{~g} / \mathrm{L}$. However, total GA 
TABLE 2: Intra- and interday precisions of the HPLC-ESI-MS/MS method $(n=6)$.

\begin{tabular}{|c|c|c|c|c|c|c|}
\hline \multirow{2}{*}{ Compound } & \multicolumn{3}{|c|}{ Intraday precision $(\mathrm{RSD}, \% ; n=6)$} & \multicolumn{3}{|c|}{ Interday precision $(\mathrm{RSD}, \% ; n=6)$} \\
\hline & $100 \mathrm{ppb}$ & $450 \mathrm{ppb}$ & $1500 \mathrm{ppb}$ & $100 \mathrm{ppb}$ & $450 \mathrm{ppb}$ & $1500 \mathrm{ppb}$ \\
\hline $\mathrm{Ki}$ & 2.3 & 1.2 & 3.7 & 1.1 & 7.2 & 3.4 \\
\hline$t \mathrm{ZR}$ & 1.6 & 2.7 & 5.4 & 4.8 & 6.4 & 6.1 \\
\hline iP & 3.4 & 2.8 & 6.6 & 3.4 & 1.5 & 2.5 \\
\hline iPR & 3.5 & 5.9 & 3.5 & 1.9 & 2.2 & 5.9 \\
\hline$t \mathrm{Z}$ & 4.2 & 5.3 & 4.5 & 5.3 & 2.6 & 3.4 \\
\hline $\mathrm{BA}$ & 4.8 & 5.4 & 7.0 & 4.2 & 3.7 & 1.3 \\
\hline DHzR & 3.7 & 3.7 & 3.2 & 5.6 & 6.2 & 2.6 \\
\hline GA3 & 5.2 & 4.6 & 4.5 & 5.3 & 1.9 & 4.5 \\
\hline GA4 & 5.4 & 2.5 & 4.2 & 4.0 & 5.7 & 5.6 \\
\hline GA7 & 3.9 & 4.0 & 5.1 & 1.4 & 4.6 & 3.4 \\
\hline IBA & 4.5 & 5.1 & 6.1 & 1.7 & 3.1 & 1.8 \\
\hline IPA & 4.7 & 3.5 & 3.4 & 3.8 & 4.5 & 3.2 \\
\hline ICA & 3.6 & 1.9 & 2.5 & 5.3 & 1.5 & 5.2 \\
\hline IAA & 3.0 & 2.4 & 4.7 & 5.2 & 2.2 & 6.2 \\
\hline
\end{tabular}

Algal biomass samples used were of C. sorokiniana TH01 grown phototrophically in BG-11 medium. Kinetin (Ki), trans-zeatin riboside (tZR), isopentenyladenine (iP), $\mathrm{N}(6)$-isopentenyladenosine (iPR), trans-zeatin $(t Z)$, 6-benzylaminopurine (BA), dihydrozeatin riboside (DHzR), gibberellic acid (GA3), gibberellin A4 (GA4), gibberellin A7 (GA7), indole-3-butyric acid (IBA), 3-indolepropionic acid (IPA), indole-3-carboxylic acid (ICA), and indole-3acetic acid (IAA).

TABle 3: Specific growth rate, biomass concentration, and lipid contents of $C$. sorokiniana TH01 grown under different conditions $(n=3)$.

\begin{tabular}{lcccc}
\hline Cultivation mode & Chemical added & Specific growth rate (1/day) & Biomass concentration (g/L) & Lipid content (\% DCW) \\
\hline Phototrophic $^{\mathrm{a}}$ (control, indoor) & - & $0.72 \pm 0.55$ & $0.96 \pm 0.06$ & $19.13 \pm 2.54$ \\
Phototrophic $^{\mathrm{a}}$ (indoor) & $5 \mathrm{~g} / \mathrm{l} \mathrm{NaCl}$ & $0.68 \pm 0.21$ & $0.82 \pm 0.33$ & $24.34 \pm 4.56$ \\
Phototrophic $^{\mathrm{a}}$ (indoor) & $10 \mathrm{~g} / \mathrm{l} \mathrm{NaCl}$ & $0.54 \pm 0.12$ & $0.75 \pm 0.46$ & $33.48 \pm 5.11$ \\
Phototrophic $^{\mathrm{a}}$ (indoor) & $15 \mathrm{~g} / \mathrm{l} \mathrm{NaCl}$ & $0.43 \pm 0.17$ & $0.69 \pm 0.14$ & $39.75 \pm 5.39$ \\
Phototrophic $^{\mathrm{a}}$ (indoor) & $20 \mathrm{~g} / \mathrm{l} \mathrm{NaCl}$ & $0.23 \pm 0.09$ & $0.55 \pm 0.25$ & $44.23 \pm 5.98$ \\
Mixtrophic $^{\mathrm{a}}$ (indoor) & $2 \mathrm{~g} / \mathrm{l}$ glucose & $3.34 \pm 0.34$ & $2.45 \pm 0.56$ & $21.38 \pm 2.45$ \\
Mixtrophic $^{\mathrm{a}}$ (indoor) & $4 \mathrm{~g} / \mathrm{L}$ glucose & $3.63 \pm 0.85$ & $5.41 \pm 0.62$ & $29.56 \pm 3.45$ \\
Mixtrophic $^{\mathrm{a}}$ (indoor) & $6 \mathrm{~g} / \mathrm{L}$ glucose & $3.16 \pm 0.95$ & $0.93 \pm 0.15$ & $37.35 \pm 6.42$ \\
Phototrophic $^{\mathrm{b}}$ (control, outdoor) & - & $0.65 \pm 0.02$ & & $22.34 \pm 2.65$ \\
\hline
\end{tabular}

Lipid was derived as fatty acid methyl esters (FAME). DCW : dry cell weight. ${ }^{\mathrm{a} C}$. sorokiniana TH01 grown indoor in $5 \mathrm{~L}$ photobioreactors under the following conditions: light intensity of $115 \mu \mathrm{mol} / \mathrm{m}^{2} \cdot \mathrm{s}$, light dark cycle of $16 \mathrm{~h} / 8 \mathrm{~h}$, temperature of $25-27^{\circ} \mathrm{C}$, and harvesting at day 15 . ${ }^{\mathrm{b}} \mathrm{C}$. sorokiniana TH01 grown outdoor in raceway ponds in duplicate under the following conditions: light intensity of $115 \mu \mathrm{mol} / \mathrm{m}^{2} \cdot \mathrm{s}$, temperature of $24.5-27.6^{\circ} \mathrm{C}$, and harvesting at day 15 .

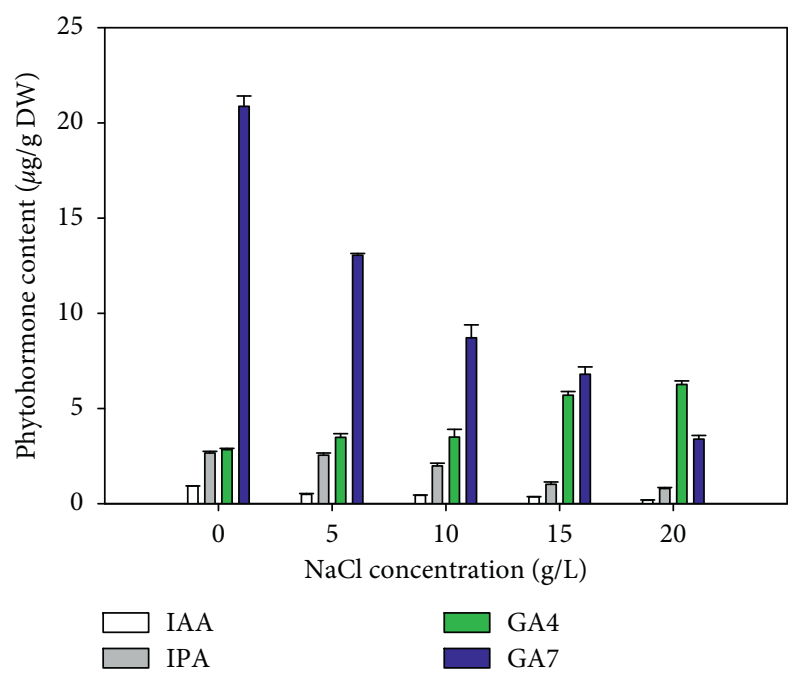

FIGURE 1: Profile and concentration of endogenous phytohormones produced by C. sorokiniana TH01 grown phototrophically in BG-11 medium under different $\mathrm{NaCl}$ concentration $(n=6$, $p<0.05)$. IAA, indole-3-acetic acid; IPA, 3-indolepropionic acid; GA4, gibberellin A4; GA7, gibberellin A7. content decreased from $23.71 \mu \mathrm{g} / \mathrm{g}$ DW to $9.65 \mu \mathrm{g} / \mathrm{g} \mathrm{DW}$ when $\mathrm{NaCl}$ concentration increased from 0 to $20 \mathrm{~g} / \mathrm{L}$. Consistently, reduction of GA levels and signalling has been shown to contribute to plant growth restriction on exposure to several stresses, including cold, salt, and osmotic stress [40].

External addition of various phytohormones to culture media has been reported to stimulate the growth and stress tolerance of various microalgae [41, 42]. However, characterization of endogenous phytohormone levels in microalgae under stress conditions is very limited [21, 43]. Nitrogen starvation (nitrogen stress) has been reported to decrease abscisic acid (ABA) and IAA levels in Acutodesmus dimorphus from 5.07 and $556.83 \mathrm{pM} / \mathrm{g}$ fresh weight (FW) (control) to 4.7 and $376.40 \mathrm{pM} / \mathrm{g} \mathrm{FW}$, respectively, in the first day of $\mathrm{N}$-starvation. However, ABA and IAA levels were observed to increase to 5.82 and $585.08 \mathrm{pM} / \mathrm{g}$ FW, respectively, when Acutodesmus dimorphus experienced the third day of N-starvation [21]. Study conducted by Lu et al. [43] also reported that transcriptional upregulation of the biosynthetic pathways of ABA occurred in N. oceanica under the $\mathrm{N}$ deficiency. Moreover, results achieved by Sulochana 
and Arumugam [44] documented an immediate increase of ABA levels to up to four folds over the control in $S$. quadricauda during the onset of $24 \mathrm{~h}$ of nitrogen deprivation; however, this ABA trend was reversed when N-starvation was continued up to $72 \mathrm{~h}$. Similarity, ABA was reported to increase its level in Dunaliella parva [45] and Draparnaldia mutabilis [19] when they were grown in conditions of salt stress and increased $\mathrm{pH}$.

3.4. Effect of Glucose Concentration on Growth, Profile, and Levels of Auxins, Cytokinins, and Gibberellins Produced by C. sorokiniana THO1 under Mixtrophic Growth. Mixtrophic growth of Chlorella sorokiniana using both sunlight and organic carbon as energy sources has been reported to achieve higher growth rate, biomass productivity [24, 46], and lipid content [25]. Therefore, the cultivation mode is also a promising strategy for achieving two targets of both biomass and lipid production for biofuel application. Data shown in Table 3 indicate that the significant increase of specific growth rate, biomass concentration, and lipid content was simultaneously observed when glucose was added as organic carbon source in BG-11 medium for mixtrophic growth of C. sorokiniana TH01. The specific growth rate, biomass concentration, and lipid content measured for C. sorokiniana TH01 were 3.34, 3.63, and 3.16 $1 /$ day; $2.45,4.41$, and $5.46 \mathrm{~g} / \mathrm{L}$; and $21.38,29.56$, and $37.36 \%$ DCW when glucose concentration was added at 2, 4, and $6 \mathrm{~g} /$ $\mathrm{L}$, respectively. Our obtained data were slightly better than data (specific growth rate of 3.20-3.40 1/day, biomass concentration of $1.66-5.08 \mathrm{~g} / \mathrm{L}$, and lipid of $13.4-34.7 \%$ DCW) reported for C. sorokiniana (UTEX 1602) grown mixtrophically in Kuhl medium supplemented with glucose concentration of 2-20 g/L [25].

Cellular metabolism of microalgae varies with variation of culture conditions. This results in changing of hormone profile as well as their concentrations. Data illustrated in Figure 2 indicate that endogenous IAA, IPA, and GA4 levels produced by C. sorokiniana TH01 were observed to increase from $0.93,2.66$, and $3.84 \mu \mathrm{g} / \mathrm{g}$ DW and peaked at 1.83, 3.25, and $7.88 \mu \mathrm{g} / \mathrm{g}$ DW when C. sorokiniana TH01 was turned from phototrophic mode (no sugar added) to mixtrophic mode with $2 \mathrm{~g} / \mathrm{L}$ glucose supplement. However, the decreased trend of IAA and GA4 contents to 0.74 and $2.98 \mu \mathrm{g} / \mathrm{g}$ DW was recorded when glucose concentration increased to $4 \mathrm{~g} / \mathrm{L}$. The IPA content was reported to disappear at glucose concentration of 4 and $6 \mathrm{~g} / \mathrm{L}$. GA 4 content also disappeared at glucose concentration of $6 \mathrm{~g} / \mathrm{L}$, while IAA was measured at $0.56 \mu \mathrm{g} / \mathrm{g}$ DW. The variation trend of endogenous GA7 of $C$. sorokiniana TH01 grown mixtrophically was decreased from 20.87 to $2.85 \mu \mathrm{g} / \mathrm{g} \mathrm{DW}$ as glucose concentration increased from 0 to $6 \mathrm{~g} / \mathrm{L}$.

Among 15 phytohormones that belonged to three groups of auxins, cytokinins, and gibberellins, C. sorokiniana TH01 was detected to produce auxins and gibberellins. The main auxins detected in C. sorokiniana TH01 were IAA with lower level than IPA. The results were in agreement with observation of Bail et al. [47] who also detected IAA, ICA, and IPA co-produced in Ectocarpus siliculosus (Phaeophyceae).

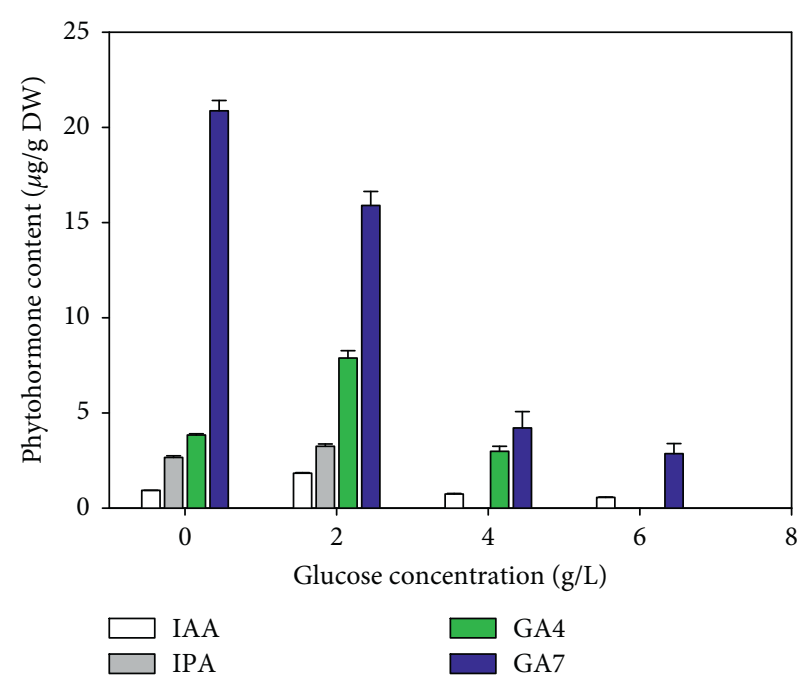

Figure 2: Profile and concentration of endogenous phytohormones produced by $C$. sorokiniana TH01 grown mixtrophically in BG-11 medium under different glucose concentration $(n=6$, $p<0.05)$. IAA, indole-3-acetic acid; IPA, 3-indolepropionic acid; GA4, gibberellin A4; GA7, gibberellin A7.

Contrastingly, study of Stirk et al. [16] reported to detect 0.50-71.49 nmol IAA/g DW and 0.18-99.83 nmol indole-3acetamide (IAM)/g DW in 19 microalgal strains (including Chlorophyceae, Trebouxiophyceae, Ulvophyceae, and Charophyceae) grown phototrophically and harvested at the exponential stage. Similarity, Jirásková et al. [48] also reported a profile of auxins produced by seven Chlorella strain harvested at the stationary phase including IAA at higher content than IAM.

The gibberellin profile produced by $C$. sorokiniana TH01 was characterized as GA4 and GA7. In the recent literature, gibberellins were all detected in the all 24 microalgal strains (including Chlorophyceae, Trebouxiophyceae, Ulvophyceae, and Charophyceae) with concentration ranging from $342.7 \mathrm{ng} / \mathrm{g}$ DW in Raphidocelis subcapitata MACC and 317-4746.1 ng/g in Scotiellopsis terrestris MACC 44 [14]. More interestingly, Stirk et al. [13] carried out a study of effect of light on growth and endogenous hormones in Chlorella minutissima which indicated that plant growth regulators (PGRs) including auxins, cytokinins, and gibberellins (GAs) were all detected in the Chlorella minutissima biomass under investigated conditions. The concentration of auxins, cytokinins, and gibberellins (GAs) were determined as $0.85-26.8 \mu \mathrm{g} / \mathrm{g}, 0.15-0.80 \mu \mathrm{g} / \mathrm{g}$, and $0.94-5.29 \mu \mathrm{g} / \mathrm{g}$, respectively. The limited number of phytohormones detected in C. sorokiniana TH01 when compared to that of other strains reported in the literature is due to the fact that profile of hormones produced by microalgae depends on the nature of species, growth conditions, nutrient conditions, and extraction and analytical techniques.

3.5. Growth, Profile, and Endogenous Auxin, Cytokinin, and Gibberellin Levels of C. sorokiniana TH01 Grown Phototrophically Outdoor. Although outdoor cultivation of microalgae in raceway ponds hardly controls algal growth 
and targeted product production, the technology is considered as an effective and inexpensive method for commercial production of algal biomass. This study used a raceway pond of $3.785 \mathrm{~m}^{2}$ [26] for pilot production of $C$. sorokiniana TH01 in BG-11 medium under outdoor conditions. Data revealed in Table 3 indicate that $C$. sorokiniana TH01 achieved specific growth rate, biomass concentration, and lipid content of $0.65 \mathrm{1} / \mathrm{day}, 0.93 \mathrm{~g} / \mathrm{L}$, and $22.34 \% \mathrm{DCW}$, respectively; these are comparable to those obtained when $C$. sorokiniana TH01 is grown phototrophically under indoor conditions. The hormone profiles characterized for C. sorokiniana TH01 grown outdoor were IAA, IPA, GA4, and GA7 with concentrations in the crude water extracts expressed as 124.6, 938.1, 75.3, and 1924.8 $\mu \mathrm{g} / \mathrm{L}$ (Table 4), which were equivalent to phytohormone levels in the algal biomass of $0.98,7.40,0.59$, and $15.18 \mu \mathrm{g} / \mathrm{g}$, respectively. The total auxins and gibberellins in the water extract were 1062.7 and $2000.1 \mu \mathrm{g} / \mathrm{L}$, respectively. The results further pointed out that levels of auxins and gibberellins produced by $C$. sorokiniana TH01 in phototrophic cultivation under outdoor conditions were notably lower than those under indoor conditions in both phototrophic and mixtrophic (with glucose concentration $<2 \mathrm{~g} / \mathrm{L}$ ) growths. The reasons for these achieved data are still unknown.

\subsection{Effect of Water Algal Extract Doses on Seed Germination} Rate. Removal of methanol and reconstitution of the dense slurry into Millipore water (equivalent to original methanol volume) resulted in a mixture containing auxins and gibberellins with total concentration of $3062.8 \mu \mathrm{g} / \mathrm{mL}$. Treatment results of rice and tomato seeds with the phytohormones mixture showed that seeds treated with algal extract having concentration greater than $1225.12 \mu \mathrm{g} / \mathrm{mL}$ $\left(0.4 C_{0}\right)$ triggered faster germination of 2 (Figure $3(\mathrm{a})$ ) and 1 days earlier (Figure 3(b)) for the seeds of tomato and rice plants, respectively, than the control group. These results are in agreement with experimental data obtained on tomato seed when treated with $A$. dimorphus culture and higher than $50 \%(\mathrm{v} / \mathrm{v})$ A. dimorphus extract concentrations [10]. Our obtained data are also well consistent with improvement rate of germination (10-50\%) of maize and wheat seeds when they were treated with Chlorella vulgaris culture harvested from both phototrophic and heterotrophic growths compared to the control experiments [11]. Moreover, germination of tomato and cucumber seeds treated with 0.17 and $0.25 \mathrm{~g} / \mathrm{L}$ of Chlorella vulgaris suspension grown phototrophically was enhanced when compared to those of the control (sterilized culture medium) [9]. Rice and tomato are considered as the most important and common vegetable plants in many countries, particularly in Vietnam. Numerous studies have been carried out on tomato to develop biostimulants, which can enhance seed germination, lateral and longitudinal root formation, and root nutrient uptake, improve total volume and vigor of the root system, and increase number of flowers and branches. In many of them, Chlorella was also tested for the tomato biostimulant. The stimulating effect of C. vulgaris was observed on tomato plant while inhibiting the growing of Meloidogyne arenaria nematode parasite [49]. It was also known in study of Oancea et al. [50] that the use of Nannochloris sp. 424-1 derived biostimulant favored the growth of non-waterstressed tomato plants. Furthermore, some of the marine algal extracts were tested on tomato seedlings with significant improvement in germination rate and plant growth. More recent study of Elhafiz et al. [51] pointed out that salttolerant C. pyrenoidosa culture improved the germination rate of cucumber and root system. The filtrate of Chlorella sorokiniana was also found to increase Triticum aestivum's length and total biomass aboveground and belowground by 30,22 , and $51 \%$, respectively [8]. Treatment of chinese chives and spinach with $0.4 \%$ Chlorella fusca culture $\left(1.5 \times 10^{7}\right.$ cells $\left./ \mathrm{mL}\right)$ not only improved the plants' growth and qualities but also decreased the gray mold disease [7]. Treatment of Beta vulgaris L. seedlings with water extract of Chlorella vulgaris and Scenedesmus quadricauda significantly improved root traits related to soil exploration and nutrient uptake such as root length, fine root length, and number of root tips than the control [33]. Moreover, the Scenedesmus quadricauda extract positively affected the growth of lettuce seedlings, presenting an increase in dry matter, chlorophylls, carotenoids, and proteins and influencing the activities of several enzymes involved in the primary metabolism [32].

It is obvious that the biostimulating effect of microalgal culture and algal extract on the enhancement of seed germination, plant growth, and plant quanlity are partially from active phytohormones such as auxins and gibberellins (characterized in this study) and cytokinins and kinetins reported in [50]. Moreover, the microalgal extracts also contained various active compounds such as proteins, carbohydrates, vitamins, and elemental compositions [52]. Recent studies have demonstrated that auxin controls seed dormancy [53] and exogenous auxin treatment represses plant seed (e.g., soybean) germination by enhancing ABA biosynthesis [54], whereas treatment with exogenous GA (e.g., GA3) improved seed germination and seedling of Masson pine (Pinus massoniana Lamb.) [55]. Our data indicated that Millipore water extract of $C$. sorokiniana TH01 contains both auxins and gibberellins with total concentration of 1062.7 and $2000.1 \mu \mathrm{g} / \mathrm{L}$, respectively, representing gibberellin concentration is almost 2 -fold higher than that of auxins. Thus, the enhancement of tomato and rice seed germination was attributed to the promoting role of gibberellins in the crude algal extract. Moreover, the active concentration of auxins and gibberellins for triggering earlier germination of seeds of rice and tomato plants was determined as 425.08 and $800.04 \mu \mathrm{g} / \mathrm{L}$, respectively.

In summary, although many endogenous phytohormones of other groups including cytokinins, brassinosteroids, and abscisic acid possibly produced by microalgae have not yet been characterized in C. sorokiniana TH01, it is obvious that the algal strain produced auxins and gibberellins under both phototrophic and mixtrophic cultivations. Moreover, the lipid content produced by C. sorokiniana TH01 under both cultivation modes was measured in the range of $19.13-44.23 \% \mathrm{DCW}$, which are pretty high for effective lipid extraction with good recovery. In addition, the 
TABLE 4: Summary of endogenous phytohormones analyzed in crude methanol extract of $C$. sorokiniana TH01 grown outdoor in raceway pond $(n=3, p<0.05)$.

Sample

IAA $(\mu \mathrm{g} / \mathrm{L}) \quad$ IPA $(\mu \mathrm{g} / \mathrm{L}) \quad$ GA4 $(\mu \mathrm{g} / \mathrm{L}) \quad$ GA7 $(\mu \mathrm{g} / \mathrm{L})$

Material recovered from methanol residual and reconstituted in Millipore water $\quad 124.6 \pm 3.5 \quad 938.1 \pm 15.8 \quad 75.3 \pm 4.8 \quad 1924.8 \pm 46.9$

IAA, indole-3-acetic acid; IPA, 3-indolepropionic acid; GA4, gibberellin A4; GA7, gibberellin A7.

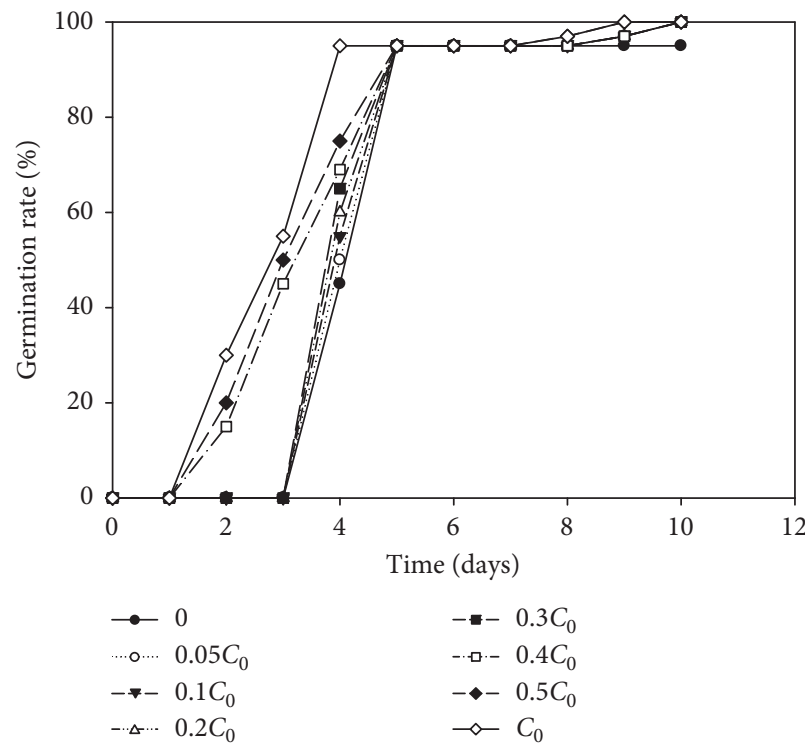

(a)

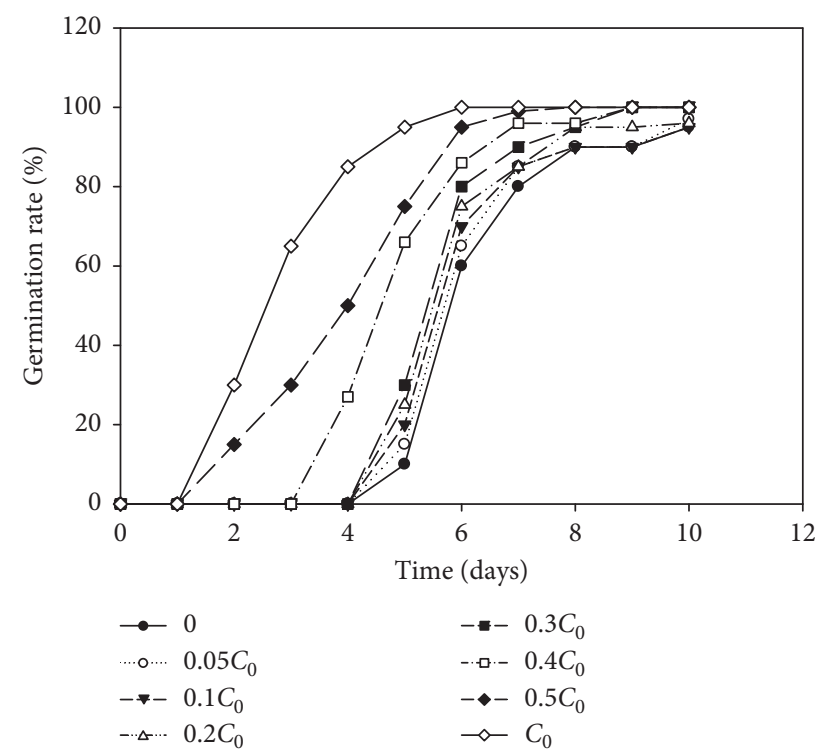

(b)

FIGURE 3: Seed germination percentage in control and algal residual-treated plants of tomato (a) and rice (b) $(n=3$, $p<0.05)$. Total phytohormone concentration, $C_{0}=1062.7$ (auxins, $\mu \mathrm{g} / \mathrm{L}$ ) +2000.1 (gibberellins, $\mu \mathrm{g} / \mathrm{L}$ ) $=3062.8 \mu \mathrm{g} / \mathrm{L}$.

material recovered from methanol residual which was achieved from lipid extraction of the algal biomass contained measurable amount of IAA, IPA, GA4, and GA7 with total auxin and gibberellin concentration of 1062.7 and $2000.1 \mu \mathrm{g} /$ L, respectively, making it a potential biomaterial (i.e., biostimulant) for crop research. Although much research studies are needed to develop a comprehensive microalgaebased biorefinery, our preliminary results pointed out that lipids of C. sorokiniana TH01 recovered from solvent extraction could be used for biofuel production and residual biomass could be used for feed/food formulation and/or biocomposite fabrication [56]. The remaining methanol residual can be used to recover methanol and obtain a concentrated material for agricultural research.

\section{Conclusion}

We have successfully determined that auxins (IAA and IPA) and gibberellins (GA4 and GA7) were endogenous phytohormones produced by $C$. sorokiniana TH01 under both phototrophic and mixtrophic cultivation modes. The reduction of auxin and GA levels under salt-stress phototrophic growth and decrease of GAs under mixtrophic growth were new findings. Moreover, the material recovered from methanol residual after lipid extraction of C. sorokiniana TH01 contained auxins and GAs which exhibited a stimulating effect on earlier seed germination of rice and tomato plants at concentration of 425.08 and $800.04 \mu \mathrm{g} / \mathrm{L}$ when it was reconstituted into Millipore water, respectively. Our trial data demonstrate $C$. sorokiniana TH01 is a promising candidate for biorefinery.

\section{Data Availability}

The data used to support the findings of this study are included within the article.

\section{Conflicts of Interest}

The authors declare that there are no conflicts of interest regarding the publication of this paper.

\section{Acknowledgments}

This research was funded by the Graduate University of Science and Technology under grant no. GUST.STS.ĐT2017-MT01.

\section{Supplementary Materials}

Table S1: response characteristics of the phytohormone standards using HPLC-ESI-MS/MS. Table S2: linear regression data for fourteen phytohormones $(n=6)$. Figure S1: structure of the fourteen plant hormones. Figure S2: spectra and retention time of phytohormones under positive scan 
mode (concentration of $500 \mathrm{ppb}$ ). Figure S3: spectra and retention time of phytohormones under negative scan mode (concentration of $500 \mathrm{ppb}$ ). Figure S4: representative HPLCESI-MS/MS spectra of algal extract of C. sorokiniana TH01 under positive scan (a) and negative scan (b) mode. IAA, indole-3-acetic acid; IPA, 3-indolepropionic acid; GA4, gibberellin A4; GA7, gibberellin A7. (Supplementary Materials)

\section{References}

[1] D. Ronga, E. Biazzi, K. Parati, D. Carminati, E. Carminati, and A. Tava, "Microalgal biostimulants and biofertilisers in crop productions," Agronomy, vol. 9, no. 4, p. 192, 2019.

[2] A. Dmytryk and K. W. Chojnacka, "Algae as fertilizers, biostimulants, and regulators of plant growth," in Algae Biomass: Characteristics and Applications: Towards AlgaeBased Products, K. Chojnacka, P. P. Wieczorek, G. Schroeder, and I. Michalak, Eds., Springer International Publishing, Cham, Switzerland, pp. 115-122, 2018.

[3] M. U. Nethravathy, J. G. Mehar, S. N. Mudliar, and A. Y. Shekh, "Recent advances in microalgal bioactives for food, feed, and healthcare products: commercial potential, market space, and sustainability," Comprehensive Reviews in Food Science and Food Safety, vol. 18, no. 6, pp. 1882-1897, 2019.

[4] N. Yan, C. Fan, Y. Chen, and Z. Hu, "The potential for microalgae as bioreactors to produce pharmaceuticals," International Journal of Molecular Sciences, vol. 17, no. 6, p. 962, 2016.

[5] M. Nicoletti, "Microalgae nutraceuticals," Foods, vol. 5, no. 3, p. 54, 2016.

[6] J. Singh and S. Gu, "Commercialization potential of microalgae for biofuels production," Renewable and Sustainable Energy Reviews, vol. 14, no. 9, pp. 2596-2610, 2010.

[7] M.-J. Kim, C.-K. Shim, Y.-K. Kim et al., "Effect of biostimulator Chlorella fusca on improving growth and qualities of Chinese Chives and Spinach in organicfarm," The Plant Pathology Journal, vol. 34, no. 6, pp. 567-574, 2018.

[8] R. Kholssi, E. A. N. Marks, J. Miñón, O. Montero, A. Debdoubi, and C. Rad, "Biofertilizing effect of Chlorella sorokiniana suspensions on wheat growth," Journal of Plant Growth Regulation, vol. 38, no. 2, pp. 644-649, 2019.

[9] F. A. Faheed and Z. A. E Fattah, "Effect of Chlorella vulgaris as bio-fertilizer on growth parameters and metabolic aspects of Lettuce plant," Journal of Agriculture \& Social Sciences, vol. 4, no. 4, pp. 165-169, 2008.

[10] J. Garcia-Gonzalez and M. Sommerfeld, "Biofertilizer and biostimulant properties of the microalga Acutodesmus dimorphus," Journal of Applied Phycology, vol. 28, no. 2, pp. 1051-1061, 2016.

[11] O. Uysal, F. O. Uysal, and K. Ekinci, "Evaluation of microalgae as microbial fertilizer," European Journal of Sustainable Development, vol. 4, no. 2, pp. 77-82, 2015.

[12] R. E. Prieto, N. M. Cordoba, A. M. Montenegro, and G. E. González-Mariño, "Production of indole-3-acetic acid in the culture medium of microalga Scenedesmus obliquus (UTEX 393)," Journal of the Brazilian Chemical Society, vol. 22, no. 12, pp. 2355-2361, 2011.

[13] W. A. Stirk, P. Bálint, D. Tarkowská et al., "Effect of light on growth and endogenous hormones in Chlorella minutissima (Trebouxiophyceae)," Plant Physiology and Biochemistry, vol. 79, pp. 66-76, 2014.
[14] W. A. Stirk, P. Bálint, D. Tarkowská et al., "Hormone profiles in microalgae: gibberellins and brassinosteroids," Plant Physiology and Biochemistry, vol. 70, pp. 348-353, 2013.

[15] W. A. Stirk, O. Novák, V. Hradecká et al., "Endogenous cytokinins, auxins and abscisic acid in Ulva fasciata (Chlorophyta) and Dictyota humifusa (Phaeophyta): towards understanding their biosynthesis and homoeostasis," European Journal of Phycology, vol. 44, no. 2, pp. 231-240, 2009.

[16] W. A. Stirk, V. Ördög, O. Novák et al., "Auxin and cytokinin relationships in 24 microalgal strains1," Journal of Phycology, vol. 49, no. 3, pp. 459-467, 2013.

[17] W. A. Stirk, V. Ördög, J. Van Staden, and K. Jäger, "Cytokinin-and auxin-like activity in Cyanophyta and microalgae," Journal of Applied Phycology, vol. 14, no. 3, pp. 215-221, 2002.

[18] W. A. Stirk, J. Van Staden, O. Novák et al., "Changes in endogenous cytokinin concentrations in chlorella (Chlorophyceae) in relation to light and the cell Cycle1," Journal of Phycology, vol. 47, no. 2, pp. 291-301, 2011.

[19] R. Hirsch, W. Hartung, and H. Gimmler, "Abscisic acid content of algae under stress," Botanica Acta, vol. 102, no. 4, pp. 326-334, 1989.

[20] E. Žižková, M. Kubeš, P. I. Dobrev et al., "Control of cytokinin and auxin homeostasis in cyanobacteria and algae," Annals of Botany, vol. 119, no. 1, pp. 151-166, 2017.

[21] K. Chokshi, I. Pancha, A. Ghosh, and S. Mishra, "Nitrogen starvation-induced cellular crosstalk of ROS-scavenging antioxidants and phytohormone enhanced the biofuel potential of green microalga Acutodesmus dimorphus," Biotechnology for Biofuels, vol. 10, no. 1, p. 60, 2017.

[22] J. Ding, L.-J. Mao, S.-T. Wang, B.-F. Yuan, and Y.-Q. Feng, "Determination of endogenous brassinosteroids in plant tissues using solid-phase extraction with double layered cartridge followed by high-performance liquid chromatography-tandem mass spectrometry," Phytochemical Analysis, vol. 24, no. 4, pp. 386-394, 2013.

[23] S. D. S. Chiwocha, S. R. Abrams, S. J. Ambrose et al., "A method for profiling classes of plant hormones and their metabolites using liquid chromatography-electrospray ionization tandem mass spectrometry: an analysis of hormone regulation of thermodormancy of lettuce (Lactuca sativa L.) seeds," The Plant Journal, vol. 35, no. 3, pp. 405-417, 2003.

[24] S. Kim, J.-e. Park, Y.-B. Cho, and S.-J. Hwang, "Growth rate, organic carbon and nutrient removal rates of Chlorella sorokiniana in autotrophic, heterotrophic and mixotrophic conditions," Bioresource Technology, vol. 144, pp. 8-13, 2013.

[25] T. Li, Y. Zheng, L. Yu, and S. Chen, "Mixotrophic cultivation of a Chlorella sorokiniana strain for enhanced biomass and lipid production," Biomass and Bioenergy, vol. 66, pp. 204213, 2014.

[26] D. T. Tran, T. C. Van Do, Q. T. Nguyen, and T. G. Le, "Simultaneous removal of pollutants and high value biomaterials production by Chlorella variabilis TH03 from domestic wastewater," Clean Technologies and Environmental Policy, 2020.

[27] E. Koutra, P. Tsafrakidou, M. Sakarika, and M. Kornaros, "Chapter 11-Microalgal biorefinery," in Microalgae Cultivation for Biofuels Production, A. Yousuf, Ed., pp. 163-185, Academic Press, Cambridge, MA, USA, 2020.

[28] J. A. Callejo-López, M. Ramírez, J. Bolívar, and D. Cantero, "Main variables affecting a chemical-enzymatic method to obtain protein and amino acids from resistant microalgae," Journal of Chemistry, vol. 2019, Article ID 1390463, 10 pages, 2019.

[29] M. Hayes, H. Skomedal, K. Skjånes et al., "15-microalgal proteins for feed, food and health," in Microalgae-Based 
Biofuels and Bioproducts, C. Gonzalez-Fernandez and R. Muñoz, Eds., Woodhead Publishers, Cambridge, UK, pp. 347-367, 2017.

[30] K. S. Khoo, K. W. Chew, G. Y. Yew et al., "Recent advances in downstream processing of microalgae lipid recovery for biofuel production," Bioresource Technology, vol. 304, Article ID 122996, 2020.

[31] M. G. de Morais, B. d. S. Vaz, E. G. de Morais, and J. A. V. Costa, "Biologically active metabolites synthesized by microalgae," BioMed Research International, vol. 2015, Article ID 835761, 15 pages, 2015.

[32] I. Puglisi, E. La Bella, E. I. Rovetto, A. R. Lo Piero, and A. Baglieri, "Biostimulant effect and biochemical response in lettuce seedlings treated with a Scenedesmus quadricauda extract," Plants, vol. 9, no. 1, p. 123, 2020.

[33] V. Barone, A. Baglieri, P. Stevanato et al., "Root morphological and molecular responses induced by microalgae extracts in sugar beet (Beta vulgaris L.)," Journal of Applied Phycology, vol. 30, no. 2, pp. 1061-1071, 2018.

[34] V. Barone, I. Puglisi, F. Fragalà, P. Stevanato, and A. Baglieri, "Effect of living cells of microalgae or their extracts on soil enzyme activities," Archives of Agronomy and Soil Science, vol. 65 , no. 5, pp. 712-726, 2019.

[35] L. M. L. Laurens, T. A. Dempster, H. D. T. Jones et al., “Algal biomass constituent analysis: method uncertainties and investigation of the underlying measuring chemistries," Analytical Chemistry, vol. 84, no. 4, pp. 1879-1887, 2012.

[36] X. Ji, J. Cheng, D. Gong et al., "The effect of $\mathrm{NaCl}$ stress on photosynthetic efficiency and lipid production in freshwater microalga-Scenedesmus obliquus XJ002," Science of The Total Environment, vol. 633, pp. 593-599, 2018.

[37] J. Church, J.-H. Hwang, K.-T. Kim et al., "Effect of salt type and concentration on the growth and lipid content of Chlorella vulgaris in synthetic saline wastewater for biofuel production," Bioresource Technology, vol. 243, pp. 147-153, 2017.

[38] H. Du, H. Liu, and L. Xiong, "Endogenous auxin and jasmonic acid levels are differentially modulated by abiotic stresses in rice," Frontiers in Plant Science, vol. 4, p. 397, 2013.

[39] H. Du, N. Wu, Y. Chang, X. Li, J. Xiao, and L. Xiong, "Carotenoid deficiency impairs ABA and IAA biosynthesis and differentially affects drought and cold tolerance in rice," Plant Molecular Biology, vol. 83, no. 4-5, pp. 475-488, 2013.

[40] E. H. Colebrook, S. G. Thomas, A. L. Phillips, and P. Hedden, "The role of gibberellin signalling in plant responses to abiotic stress," Journal of Experimental Biology, vol. 217, no. 1, pp. 67-75, 2014.

[41] E.-S. Salama, A. N. Kabra, M.-K. Ji, J. R. Kim, B. Min, and B.-H. Jeon, "Enhancement of microalgae growth and fatty acid content under the influence of phytohormones," Bioresource Technology, vol. 172, pp. 97-103, 2014.

[42] J. Liu, W. Qiu, and Y. Song, "Stimulatory effect of auxins on the growth and lipid productivity of Chlorella pyrenoidosa and Scenedesmus quadricauda," Algal Research, vol. 18, pp. 273280, 2016.

[43] Y. Lu, D. Tarkowská, V. Turečková et al., “Antagonistic roles of abscisic acid and cytokinin during response to nitrogen depletion in oleaginous microalgaNannochloropsis oceanicaexpand the evolutionary breadth of phytohormone function," The Plant Journal, vol. 80, no. 1, pp. 52-68, 2014.

[44] S. B. Sulochana and M. Arumugam, "Influence of abscisic acid on growth, biomass and lipid yield of Scenedesmus quadricauda under nitrogen starved condition," Bioresource Technology, vol. 213, pp. 198-203, 2016.
[45] A. Tietz, U. Ruttkowski, R. Kohler, and W. Kasprik, "Further investigations on the occurrence and the effects of abscisic acid in algae," Biochemie und Physiologie der Pflanzen, vol. 184, no. 3-4, pp. 259-266, 1989.

[46] Y.-K. Lee, S.-Y. Ding, C.-H. Hoe, and C.-S. Low, "Mixotrophic growth of Chlorella sorokiniana in outdoor enclosed photobioreactor," Journal of Applied Phycology, vol. 8, no. 2, pp. 163-169, 1996.

[47] A. L. Bail, B. Billoud, N. Kowalczyk et al., "Auxin metabolism and function in the multicellular brown alga Ectocarpus siliculosus," Plant Physiology, vol. 153, no. 1, pp. 128-144, 2010.

[48] D. Jirásková, A. Poulíčková, O. Novák, K. Sedláková, V. Hradecká, and M. Strnad, "High-throughput screening technology for monitoring phytohormone production in microalgae," Journal of Phycology, vol. 45, no. 1, pp. 108-118, 2009.

[49] B. Choleva, T. Bileva, Y. Tzvetkov, and P. Barakov, "Preliminary study of the green algae chlorella (Chlorella vulgaris) for control on the root-knot nematode (Meloidogyne arenaria) in tomato plants and ectoparasite Xiphinema indexin grape seedlings," Communications in Agricultural and Applied Biological Sciences, vol. 70, no. 4, pp. 915-926, 2005.

[50] F. Oancea, S. Velea, V. Fatu, C. Mincea, and L. Ilie, "Microalgae based plant biostimulant and its effect on water stressed tomato plants," Romanian Journal of Plant Protection, vol. 6, pp. 104-117, 2013.

[51] A. A. Elhafiz, A. A. Elhafiz, S. S. Gaur, N. Hamdany, M. Osman, and T. V. R. Lakshmi, "Chlorella vulgaris and Chlorella pyrenoidosa live cells appear to be promising sustainable biofertilizer to grow rice, lettuce, cucumber and eggplant in the UAE soils," Recent Research in Science and Technology, vol. 7, pp. 14-21, 2015.

[52] C. Mutale-Joan, B. Redouane, E. Najib et al., "Screening of microalgae liquid extracts for their bio stimulant properties on plant growth, nutrient uptake and metabolite profile of Solanum lycopersicum L," Scientific Reports, vol. 10, no. 1, Article ID 2820, 2020.

[53] X. Liu, H. Zhang, Y. Zhao et al., "Auxin controls seed dormancy through stimulation of abscisic acid signaling by inducing ARF-mediated ABI3 activation in Arabidopsis," Proceedings of the National Academy of Sciences, vol. 110, no. 38, pp. 15485-15490, 2013.

[54] H. Shuai, Y. Meng, X. Luo et al., "Exogenous auxin represses soybean seed germination through decreasing the gibberellin/ abscisic acid (GA/ABA) ratio," Scientific Reports, vol. 7, no. 1, Article ID 12620, 2017.

[55] Z. Guangwu and J. Xuwen, "Roles of gibberellin and auxin in promoting seed germination and seedling vigor in Pinus massoniana," Forest Science, vol. 60, no. 2, pp. 367-373, 2013.

[56] D.-T. Tran, H. R. Lee, S. Jung, M. S. Park, and J.-W. Yang, "Lipid-extracted algal biomass based biocomposites fabrication with poly (vinyl alcohol)," Algal Research, vol. 31, pp. $525-533,2018$. 